\title{
XI
}

\section{A AMAZÔNIA (R)EXISTE: PROTAGONISMO, LUTA POR DIREITOS HUMANOS E CONTRIBUTOS DA OSC SEARA PARA A INCLUSÃO SOCIAL*}

\author{
Bárbara Tereza Costa do Nascimento ${ }^{1}$ \\ Cleilma Sousa Rodrigues Riker ${ }^{2}$ \\ Narelly Tavares Rodrigues e Melo ${ }^{3}$
}

\section{Amazônia na perspectiva das questões sociais}

A Amazônia legal vai além do bioma amazônico, tem 20\% do bioma do cerrado e parte do Pantanal mato-grossense, é o mais extenso dos biomas brasileiros e corresponde a $1 / 3$ das florestas tropicais unidas do planeta. Formada por nove estados (Acre, Amapá, Amazonas, Mato Grosso, Pará, Rondônia, Roraima, Tocantins e parte do Maranhão), a Amazônia detém a mais elevada biodiversidade, o maior banco genético e a maior reserva de água potável do mundo e possui duas grandes metrópoles com população acima de um milhão de habitantes, cada uma, a saber: Manaus, capital do Amazonas, e Belém, capital do Pará, sendo que a população paraense é maior e se concentra na porção oriental e parte da região atlântica. No aspecto populacional, a região amazônica brasileira possui $12,32 \%$ do total de habitantes do país, com adensamento de 3,6 $\mathrm{hab} / \mathrm{km}^{\mathrm{a}}$, refletindo o caráter de "floresta urbanizada", onde cerca de $60 \%$ da sua população concentra-se nas áreas urbanas $\left(15 \mathrm{hab} / \mathrm{km}^{\mathrm{a}}\right)$, enquanto a área rural possui uma ocupação difusa reservada aos grupos marginalizados, como migrantes nordestinos, indígenas, ribeirinhos e

\footnotetext{
*DOI - 10.29388/978-65-86678-45-1-0-f.261-286

${ }^{1}$ Mestranda do Programa de Pós Graduação em Educação da Universidade Federal do Oeste do Pará (UFOPA). e-mail: barbaratereza.c@gmail.com

${ }^{2}$ Mestranda do Programa de Pós Graduação em Educação da Universidade Federal do Oeste do Pará (UFOPA). e-mail: cleylmaa@gmail.com

${ }^{3}$ Mestranda do Programa de Pós Graduação em Educação da Universidade Federal do Oeste do Pará (UFOPA). e-mail: narelrodrigues@,outlook.com
} 
quilombolas (IBGE, 2010; LACERDA; VERONESE, 2017). Atualmente, a Amazônia é considerada o berço da maioria dos povos indígenas, que ocupam o continente, e nela vivem cerca 23 milhões de brasileiros, dentre estes, cerca de 55,9\% da população indígena brasileira (IBGE, 2010).

Historicamente, a Amazônia foi constituída nos diversos imaginários sociais estrangeiros como paraíso terrestre ou El Dourado. Segundo Paes Loureiro, “essa visão magnífica da Amazônia, tem razão de ser em decorrência de sua real exuberância de natureza e paisagem na PanAmazônia" (LOUREIRO, 2019). Mas nas últimas décadas, esta visão foi convertida em um tema complexo, com inúmeros dilemas e problemas a serem resolvidos. E, para melhor compreensão de tais dilemas, faz-se necessário rememorar o início do processo de invasão, apropriação e violência, conhecido na sua historiografia como colonização (ANDRADE, 2017).

Descrita incialmente pelo navegador espanhol Vicente Pinzón, em 1.500, como paraíso terrestre (PORTO-GONÇALVES, 2017), em razão da sua biodiversidade e multiculturalidade, no decorrer dos séculos, a Amazônia tem sofrido inúmeros ataques e passa por mudanças, por causa de uma série de conflitos de interesses econômicos, políticos e sociais, que caracterizam a pós-modernidade. Tais conflitos, evidenciam uma demanda social pautada na necessidade de dialogar em busca de resoluções para os problemas sociais e ambientais impostos à região, afetada nos ecossistemas que formam a sua biodiversidade (ANDRADE, 2018).

Neste aspecto, a dialética que retrata as imagens da Amazônia como "paraíso terrestre, de pulmão do mundo, de fonte inesgotável de recursos naturais e de região do futuro; na mesma medida em que se aproximam de inferno verde, cidades e populações invisíveis, vazio demográfico e cultural, entre outras" (ANDRADE, 2014; PORTOGONÇALVES, 2017), é vista de maneira crítica. Pois, evidencia que, para além das diversas representações, existe uma realidade que é comum aos habitantes e à natureza amazônica. E em meio a esta realidade estão os diversos conflitos que provocaram inúmeras consequências ambientais, educacionais e sociais e que, na mesma proporção, afetam as popula- 
ções mais vulneráveis socioeconomicamente e vítimas do racismo ambiental (ACSELRAD, 2010; LIMA, 2014).

Hodiernamente, a realidade das condições sociais, econômicas e ambientais em que se encontra a Amazônia, remete ao fato de que falar sobre estas questões na região, perpassa por vários eixos, por tratar-se de um tema transversal. É possível dizer que devido às origens no colonialismo e posteriormente no assistencialismo, a questão social no contexto amazônico mostra-se historicamente atrelada aos interesses de integração comercial de suas riquezas naturais e ocupação populacional de seus espaços. Isto ocorre, especialmente, quando a região é incorporada ao domínio do Estado português e sua ampliação territorial passou a ter prioridade na política e ao longo de sua história, onde evidenciam-se os objetivos específicos na maioria das intervenções propagadas pelo Estado, no contexto da integração econômica e da ocupação territorial (LACERDA; VERONESE, 2017).

Este preâmbulo objetiva caracterizar a questão social contemporânea e alguns de seus principais aspectos, principalmente, no que se refere às contribuições para com as populações nativas, onde geralmente se verifica posturas de desconsideração e desrespeito tanto com a preservação, quanto com a manutenção dos aspectos e das condições necessárias ou garantias para a vida destas populações, e de seus aspectos culturais, diversos e singulares. A partir da entrada dos colonos e da exploração da mão-de-obra indígena, que ocorre a instalação e intensificação da atividade comercial na região (LACERDA; VERONESE, 2017).

No contexto colonial, historicamente, a exploração tende a aproximar cada vez mais a Amazônia da esfera capitalista comercial. Por conseguinte, a era capitalista industrial, que previa relação harmônica e evolutiva entre crescimento econômico e desenvolvimento social, termina por promover processos degradantes de exploração e inclusão perversa de seres humanos, que passaram a ser privados de suas necessidades básicas e de seus direitos fundamentais, gerando um cenário de múltiplas desigualdades sociais (LACERDA; VERONESE, 2017). Conforme Mészáros,

[...] vivemos numa ordem social na qual mesmo os requisitos 
mínimos da realização humana são insensivelmente negados à esmagadora maioria da humanidade, enquanto a produção de desperdício assumiu proporções proibitivas, de acordo com a mudança da reclamada "destruição produtiva" do capitalismo no passado para a realidade mais dominante hoje da produção destrutiva. As desigualdades sociais gritantes em evidência atualmente, e ainda mais pronunciadas no seu desvelado desenvolvimento (MÉSZÁROS, 2005).

Em relação às desigualdades, Mészáros (2005) diz que vivemos sob condições de alienação desumanizante e ainda de subversão fetichista do estado real de coisas dentro da consciência, a qual caracteriza como "reificação". Um exemplo dessa desumanização se encontra nos trinta anos de espera pela conclusão da rodovia Transamazônica (BR 230), um polêmico projeto que corta Amazônia ao meio. A estrada passa por diversas reservas indígenas e ambientais, áreas de garimpo e regiões de graves conflitos fundiários, onde

[...] grilagem de terras, expropriação de antigos habitantes e populações indígenas, extração criminosa de madeira e minério, ausência do Estado, trabalho escravo, desmatamento, organizações criminosas entrelaçam-se, são íntimas, e têm em comum a violência, uma violência contra o mais fraco, seja ele o índio, o camponês ou o mogno (TORRES, 2005).

Neste exemplo, vemos que são muitos os fatores que têm impulsionado uma série de problemas ambientais e sociais na Amazônia e que existe uma comercialização, onde a supervalorização do capital econômico e o descaso ambiental, incrementam as atividades econômicas, desvinculado de uma política ambiental coerente com a realidade, e alteram consideravelmente as dinâmicas ambientais na região (ANDRADE; CARIDE, 2016). Assim, dentre as principais atividades que têm contribuído e agravado os mais diversos problemas desde meados do século passado, também destacam-se: as usinas de hidrelétricas construídas em áreas tropicais; no Estado do Pará, os portos de Itaituba e de Santarém contribuíram e ainda contribuem para o aumento da derrubada da flores- 
ta e, consequentemente, para a perda da biodiversidade, assim como as atividades de mineração, que, historicamente, têm atraído a atenção de grandes investidores tanto nacionais e como internacionais (ANDRADE, 2018).

Consequentemente, para além dos megaprojetos de rodovias, de hidrelétricas e da mineração, a Amazônia é atingida pelas atividades a eles relacionadas e pelos processos de poluição, degradação e impactos sociais, os quais contribuíram para a perda da biodiversidade e das condições básicas de subsistência das populações do campo, principalmente os indígenas, pescadores artesanais e caboclos ribeirinhos (FEARNSIDE, 2015). E, em meio a tudo isso, estão as estratégias de invisibilização da população local, a desvalorização da sua cultura e, especialmente, a desqualificação dos seus saberes (ANDRADE, 2014).

Todavia, em contrapartida a essas estratégias, os amazônidas resistem na tentativa em desarticular a rede de interesses e poder que supervaloriza o capital econômico, no âmbito da participação e dos movimentos sociais, dentre os quais destacamos: a Revolta da Cabanagem (1835-1840); o Manifesto do Rio Negro (1970); o Manifesto Ecológico de José Lutzenberger - "Fim do Futuro? Manifesto ecológico brasileiro" (1976); a Aliança dos povos da Floresta, liderada por Chico Mendes, (1980); e o Movimento Xingu Vivo para Sempre (ANDRADE; CARIDE 2016). Estes movimentos surgiram em resistência aos problemas e questões que têm reforçado uma rede de exclusão social e problemáticas ambientais enquanto resultado da colonização, das políticas de "povoamento" e de comercialização da Amazônia (PORTOGONÇALVES, 2017).

Aliada a estes movimentos, a educação tem papel fundamental, especialmente no que se refere à resistência, quando toma a dimensão de um processo contraditório e de disputas. Como processo humano por excelência e dinâmico da sociedade, ela discorre sobre os debates do seu tempo e produz resistências, continuidades e ideologias, pois "toda educação expressa os embates de um período histórico, pois é em seu interior que estão em disputa os projetos de formação humana, tanto no presente, como para o futuro" (SILVA JÚNIOR, 2019). Entretanto restam aos movimentos e coletivos sociais a construção das condições subjetivas 
que promovam uma formação político educativa voltada para a emancipação. (SILVA JÚNIOR, 2019).

Neste sentido, considerando os aspectos sociais, culturais, ambientais e produtivos locais em articulação com as realidades nacional e mundial, bem como a participação do professor e da população no contexto amazônico, Ribeiro e Brasileiro (2017) corroboram com esse pensamento quando refletem sobre

[...] a importância da participação do amazônida na elaboração, implementação e acompanhamento de programas, projetos e ações para a educação pública nas escolas da Amazônia Brasileira, especialmente no Estado do Pará, considerando a heterogeneidade como uma das principais características da Região. (RIBERIRO; BRASILEIRO, 2017).

E a respeito da heterogeneidade amazônica, Moura e Ferreira (2017), chamam atenção para a diversidade linguística, cultural e ambiental, existente na região e que devem ser levadas em consideração no processo educativo e destacam que essa diversidade repercute na sala de aula, pois os alunos são parte da população heterogênea e possuem práticas culturais diferentes. Inclusive, ressaltam a importância e a necessidade de se considerar essa diversidade linguística, no contexto amazônico e bem como suas especificidades, as quais tanto contribuem para o ensino quanto para a emancipação da escola. Ao passo que, fica clara a necessidade de enfrentar estas e outras questões sociais a partir do chão da escola, adequando o currículo pedagógico às legislações educacionais vigentes, pela "necessidade de se inserir tanto as questões sociais e humanas no seu percurso formativo, [...], de forma mais efetiva nas discussões dentro dos cursos de formação de professores, dando suporte para a construção da identidade profissional do futuro docente da educação básica" (COUTINHO; BRASILEIRO; COSTA, 2018).

Destarte, pensar a Amazônia, região marcada pela exploração por parte dos grandes conglomerados de interesses empresariais, que provocam diversos conflitos e desastres sociais e ambientais, é pensar a diversidade cultural e educacional que engloba muitos aspectos de uma comuni- 
dade com etnias, línguas e suas diferentes manifestações culturais. E, nesse contexto, nos remetemos a uma realidade específica conhecida como Amazônia - região rica em recursos naturais e atrativa por apresentar na sua constituição tanto da natureza quanto da população uma heterogeneidade cultural, biológica e linguística (GOMES; CHAIBE, 2016).

Assim, pensar a Amazônia nos contextos social, educacional e ambiental dos direitos humanos parece ir em contraposição ao exercício das suas funções sociais de reprodução do capital, que desumaniza o ser humano. Diante disso, vem a necessidade de mudança. Contudo, "mudar estas condições exige uma intervenção consciente em todos os domínios e a todos os níveis da nossa existência individual e social" (MÉSZÁROS, 2005). Neste sentido, de acordo com Marx, os seres humanos devem mudar "dos pés à cabeça as condições da sua existência industrial e política, e consequentemente toda a sua maneira de ser" (MÉSZÁROS, 2005). Então, pensar em mudança, é também pensar que ela ocorre através da educação, a qual exerce papel fundamental, para a efetivação de qualquer mudança. E mudar significa ter consciência de direitos e de luta pela dignidade humana.

E ainda, concernente à educação, em sua obra, Mészáros (2005) contempla uma ordem social qualitativamente diferente, quando defende que agora tanto é possível embarcar na estrada que nos leva até essa ordem como também é necessário e urgente. Pois, segundo ele, as incorrigíveis determinações destrutivas da ordem existente tornam imperativo contrapor aos antagonismos estruturais irreconciliáveis do sistema capitalista, uma alternativa positiva sustentável, para a regulação da reprodução metabólica social, se quisermos assegurar as condições elementares da sobrevivência humana. Logo, o papel da educação, orientado pela única perspectiva positivamente viável de ir para além do capital, é absolutamente crucial a este propósito (MÉSZÁROS, 2005).

\section{A violação dos direitos humanos na Amazônia}

A dignidade da pessoa humana é representada nos tratados, convenções e pactos internacionais de maneira ecumênica. Isto é, há uma construção comum na agenda dos estados que discute a participação e 
acesso a uma vida digna de modo a considerar o princípio da igualdade entre os indivíduos. A este respeito, Sarlet define dignidade humana como

[...] a qualidade intrínseca e distintiva de cada ser humano que o faz merecedor do mesmo respeito e consideração por parte do Estado e da comunidade, implicando, neste sentido, um complexo de direitos e deveres fundamentais que assegurem a pessoa tanto contra todo e qualquer ato de cunho degradante e desumano, como venham a lhe garantir as condições existenciais mínimas para uma vida saudável, além de propiciar e promover sua participação ativa e corresponsável nos destinos da própria existência e da vida em comunhão com os demais seres humanos. (SARLET, 2002, p. 62)

A Declaração Universal dos Direitos Humanos de 1948 em seu Artigo $1^{\circ}$ assevera que "todos os seres humanos nascem livres e iguais em dignidade e em direitos". Fruto de um consenso geral entre as nações no período pós-guerra, o instrumento foi criado a fim de promover a fraternidade mundial e construir uma nova base ideológica para a negociação de conflitos.

O caráter universal dos direitos humanos ao positivar que somos todos livres e iguais perante a lei deixa de prever, no entanto, a complexidade humana, seja ela no aspecto individual de gênero, idade, renda; ou coletivo ao tratarmos as particularidades locais de território, cultura e concepção de valores. Segundo Outeiro e Soares a perspectiva universalista.

[...] tende a considerar que certas diferenças podem indicar inferioridade ou que a região/país ainda está em desenvolvimento [...] este conceito padece de dois vícios: ele endossa a imprescindibilidade de se atender ao critério econômico e acaba reforçando a ideia de que é necessário crescimento econômico para ser desenvolvido. (OUTEIRO; SOARES, 2017, p. 4)

Apesar dos direitos humanos buscarem, em seu processo de expansão global, a soberania popular e a garantia da liberdade como uma 
reação combativa aos diversos modos de opressão, o cotidiano hegemônico imposto pela sociedade capitalista na organização política e social do Estado cria abismos, sentenças e limitações. Apresentada sob uma perspectiva emancipatória, a internacionalização dos direitos humanos assume, contraditoriamente, conforme aponta Rodrigues um processo de relegitimação política do liberalismo e, com isso, a relegitimação da exclusão social e da exclusão das minorias culturais, étnicas e sociais, em face da nova burguesia transnacional e dos valores capitalistas globais (RODRIGUES, 2007, p. 70)

Se na esfera internacional os direitos humanos correspondem a um ideal comum a fim de atingir todos os indivíduos e órgãos da sociedade, os direitos fundamentais caracterizam um ordenamento jurídico consagrado em território nacional. De acordo com Santos, é competência do Estado prover políticas sociais que possibilitem a fruição dos direitos garantidos constitucionalmente, mediante leis, atos administrativos ou através da prestação de serviços por suas autarquias, de modo a abranger a coletividade em primeiro lugar (SANTOS, 2018, p. 94). No Brasil, a Constituição Federal promulgada em 1988 estabelece em seu Título II os Direitos e Garantias Fundamentais seccionados em cinco capítulos, são eles: Direitos Individuais e Coletivos, Direitos Sociais, Direitos de Nacionalidade, Direitos Políticos e os Direitos Relacionados à Existência.

Há muito se discute o alcance e eficácia dos Direitos e Garantias Fundamentais no território brasileiro. A constituição jurídica em uma realidade multicultural expõe fragilidades que resultam em danos à coletividade e a representatividade na formação do sujeito. O sentido equânime na aplicação do direito jurídico sofre distanciamentos e barreiras sociais de modo a não abarcar a diversidade étnica que o pluralismo no país postula. Consoante ao que defende Alves, os direitos fundamentais

[...] a fim de serem gozados em seu máximo grau de efetividade necessitam de ser reconhecidos pelo outro e aí reside o grande desafio da pós-modernidade: o reconhecimento e respeito aos direitos fundamentais do "diferente"; aquele que não se enquadra, em determinada esfera, no padrão oficial determinado pela sociedade. 
Desrespeitar os direitos fundamentais de um indivíduo é mais que mero ato ilícito com consequências jurídicas: significa romper com a construção de sua personalidade, possuindo implicações também extrajurídicas no descobrimento de seu ser. (ALVES, 2017, p. 141)

É na perspectiva da diversidade que a violação dos direitos humanos encontra passe livre para a sua proliferação. A invisibilização de grupos minoritários nos dispositivos legais bem como a deficiência de instrumentos jurídicos dotados de representatividade revela a omissão do Estado no combate às vulnerabilidades sociais. Neste cenário de ataques aos direitos individuais e coletivos da pessoa humana, a Região Amazônica é alvo fácil do discurso desenvolvimentista predatório onde, segundo afirma Rodrigues e Ribeiro, "registram-se elevados índices de violência, conflitos e degradação ambiental que se desenvolvem em torno, principalmente, de questões territoriais, indicando que mesmo em tempos atuais, ainda se constata, no Brasil, cenários remanescentes da colonização" (RODRIGUES; RIBEIRO, 2016, p. 23).

$O$ vislumbre pela produção de commodities e a exploração indiscriminada de recursos afeta a vida cotidiana das comunidades tradicionais na Amazônia. O Estado não se preocupa em reparar a invasão de propriedade e a subtração de cultura aos quais os ribeirinhos, indígenas e demais povos da floresta são expostos, pelo contrário, observa-se uma tendência de aparelhamento legislativo que capacita, cada vez mais, a relação de domínio e subordinação entre os envolvidos neste processo de industrialização e ocupação do território amazônico. A este respeito Cruz explica que

[...] o projeto de modernização conservadora materializado nos planos e planejamentos do Estado autoritário e na implantação de "grandes projetos" a partir da década de 60 via tais populações e seus modos de vida "tradicionais" como obstáculos ao "desenvolvimento", pois nessa visão se assinala um único futuro possível para todas as culturas e todos os povos: a modernização ocidental capitalista e a sociedade de consumo urbano-industrial. (CRUZ, 2006, p. 64) 
É salutar antever que o posicionamento contra hegemônico não busca o protecionismo conservador da região, de acordo com Vieira é inegável a importância do crescimento econômico e em muito o aumento da receita do Estado contribui para a concretização e universalização de direitos, no entanto, é imprescindível que a distribuição deste crescimento respeite os saberes e características locais, de modo a não acarretar o rompimento com as raízes e heranças étnico-culturais (VIEIRA, 2015, p. 94).

O ordenamento social e ambiental existente na Amazônia vem sendo descaracterizado a partir da intervenção de megaprojetos. São muitas as formas de opressão e exploração: hidrelétricas, mono cultivos, desmatamento, mineração, lutas territoriais e até especulação imobiliária, mas, o principal fator degradante e de prejuízo socioambiental permanece atrelado ao agronegócio, apesar das evidentes perdas sofridas pela Região Amazônica, esse modelo extrativista segue sendo a principal bandeira defendida pelo Estado. Segundo relatório elaborado pela Comissão Pastoral da Terra em Santarém, os impactos socioambientais do avanço do agronegócio na região, apontou que

[...] até 2010, cerca de 500 famílias deixaram suas terras para dar lugar a campos de soja no oeste do Pará. Comunidades inteiras deixaram de existir ou foram diminuídas para dar lugar aos latifúndios. O Sindicato dos Trabalhadores e Trabalhadoras Rurais (STTR) de Santarém e o Projeto Saúde Alegria mapearam, em 2008, cerca de 30 nascentes e igarapés contaminados por agrotóxicos e/ou em processo de assoreamento causado pela falta de mata ciliar, sem contar os danos às águas subterrâneas. Esses danos se verificaram em áreas próximas a plantações de soja, que também contam com registros de problemas de saúde dos moradores locais consumidores dessas fontes de água. (CADERNOS DA AMAZÔNIA, 2013)

A contribuição do povo amazônida para a ascensão do sistema global não é a exportação de matéria-prima. A participação da Amazônia no desenvolvimento é a perda de território, a exposição à doenças, a expansão da criminalidade e o genocídio de indígenas e quilombolas. Nesse 
sentido, não há como afirmar que os Direitos Humanos Universais e os Direitos e Garantias Fundamentais previstos na Constituição Federal de 1988 alcançam a demanda que a realidade amazônica postula, uma vez que o Estado dissociado do seu dever de proteção à vida é omisso aos crimes cometidos contra as diversas vivências que o Brasil apresenta. De acordo com Rodrigues a racionalidade ocidental

[...] torna-se evidente na medida em que, unida à democracia liberal e ao capitalismo global, à visão total de mundo e, portanto, de direitos humanos, parte de uma totalidade seletiva e arbitrária, visto que, tomando como ponto de partida a epistemologia ocidental e, com isso, a visão de mundo baseada em critérios ocidentais, deixa de lado a experiência cultural das minorias culturais não abrangidas pela visão ocidental de dignidade humana. (RODRIGUES, 2007, p. 74)

A luta por direitos na Amazônia é conduzida pela busca do reconhecimento identitário e participação política. O discurso dos povos tradicionais evoca a ancestralidade, memória e territorialidade que, por muitas décadas, foram ignoradas, negligenciadas e colocadas à margem da sociedade. Conforme Cruz explica, foi por meio dos movimentos sociais contra as diferentes formas de subalternização material e simbólica, contra preconceitos e estigmas e pela afirmação de suas identidades a partir dos seus próprios modos de vida que os povos tradicionais seguem desconstruindo estigmas e conquistando um protagonismo antes nunca visto (CRUZ, 2006, p. 68). A serviço desta coletividade e em virtude da ineficiência do Estado, as entidades do Terceiro Setor são grandes aliadas das comunidades tradicionais e integram a luta por equidade, justiça e liberdade. Com o objetivo de complementar as lacunas dos serviços e bens públicos, Castro e Pena (2014) destacam que essas organizações vêm

[...] crescendo e se expandindo em várias áreas, objetivando atender a demanda por serviços sociais, requisitados por uma quantidade expressiva da população menos favorecida, em vários sentidos, de que o Estado e os agentes econômicos não têm interesses 
ou não são capazes de provê-la. Seu crescimento vem em virtude, também, de práticas cada vez mais efetivas de políticas neoliberal do capitalismo global, produzindo instabilidade econômica, política e social, principalmente nos países do terceiro mundo. (CASTRO; PENA, 2014)

\section{Organizações da sociedade civil e a inclusão social na Amazônia}

Os "Centros de Educação Popular", "ONGs", "Organizações sem fins lucrativos", "Organizações sem fins econômicos" e "Organizações da Sociedade Civil" são terminologias utilizadas para identificar as Entidades que possuem "valor na constituição de redes, movimentos, plataformas e fóruns capazes de promover ação articulada, proposição e diálogo com foco em iniciativas de incidência, nacional e internacional" (ARMANI, 2013, p. 20). Mas é o termo Organização da Sociedade Civil, ou OSCs, que se destaca como uma "nova denominação genérica" que contempla essas organizações que estão presentes na área social (Idem, p. 13).

Com um histórico que vai desde a clandestinidade, como no período ditatorial brasileiro que pelo Ato Institucional no2 (AI-2) de 1965, e o Decreto-Lei no 41, de 1966, que impediam a existência de partidos políticos e das próprias entidades de assistência social; à legitimidade, como a que veio a partir da Constituição de 1988 que reconheceu como "legítima a participação cidadã nas políticas sociais, dando respaldo para tal" (RAPOSO; RAPOSO, 2014, p. 21). Anos depois, em 1992, foi a Conferência das Nações Unidas sobre o Meio Ambiente e Desenvolvimento ECO 92 - que deu protagonismo a sociedade civil organizada consultando-os para um debate importante de escala internacional. A partir dessa visibilidade e das contribuições das OSCs na história social e também educacional brasileira, o novo código civil nacional, Lei 10.406/2002 (Art. 44) e as legislações específicas; organizaram as associações, as fundações, as sociedades cooperativas e as organizações religiosas dentro dessa gama de organizações de natureza jurídica de direito privado que integram o $3^{\circ}$ Setor, que, segundo SANTOS (2001), são o 
[...] conjunto de organizações sociais que não são nem estatais nem mercantis, ou seja, organizações sociais que, por um lado, sendo privadas, não visam a fins lucrativos, e, por outro lado, sendo animadas por objetivos sociais, públicos ou coletivos, não são estatais. (SANTOS, 2001, p. 13)

Assim, as OSCs são identificadas a partir das participações da sociedade civil organizada sobre necessidades urgentes e emergentes específicas que buscam suprir carências e colaborar para a superação de problemas sociais.

ARMANI (2013, p.17) afirma que as OSCs abraçam o lugar, os atores, as visões e as agendas presentes no processo social do país, possibilitando o acesso à democracia e aos direitos dos atendidos nas OSCs e dos demais cidadãos. O protagonismo social das OSCs são o "reflexo do respeito ao pluralismo e à expressão de legítimas diferenças, assim como do exercício da tolerância como princípio de convivência social". (OLIVEIRA, 1997, p. 4 apud OLIVEIRA; HADDAD, 2001, p. 65).

\section{OSCs na Amazônia}

Na Amazônia há muitas OSCs em atuação. O Mapa das Organizações da Sociedade Civil registrou em julho de 2020 a atuação de 143.333 OSCs na extensão dos estados que compõe a Amazônia Legal. A saber: Acre com 3.196, Amapá com 2.949, Amazonas com 10.326, Maranhão com 24.309, Mato Grosso com 63.154, Pará com 21.985, Rondônia com 7.894, Roraima com 1.908 e Tocantins com 7.612,00.

Com naturezas jurídicas diversas, objetivos e finalidades específicas, nacionais e internacionais, essas OSCs somam um quantitativo grande de unidades locais, pessoal ocupado assalariado e público atendido, além das ações, projetos e programas em andamento, seja de habitação, saúde, cultura e recreação, educação e pesquisa, assistência social, religião, meio ambiente e proteção ambiental, desenvolvimento e defesa de direitos, e aqui se incluem as associações de moradores, os centros e associações comunitárias, coletivos rurais e grupos de minorias. 
Esse movimento organizado da sociedade gera "resistências em rede", que, segundo ALMEIDA, SANTOS e SOUSA (2018), fomentam formas de sobrevivência nos seus lugares de atuação.

Elas ativam empates, romarias, chamados, ocupações de áreas griladas em fazendas que cometeram crimes ambientais ou onde ocorre registro de trabalho escravo, canteiros de obras e ferrovias, acampam em órgãos públicos, criam feiras, fóruns, místicas, canções, exposições de fotografias, procissões, marchas, escolas diferenciadas, lutam pelo reconhecimento e defesa de seus territórios na busca pela amplificação da cidadania. Trata-se de um processo marcado por inúmeras mediações (setores da Igreja católica, partidos políticos, ONGs e intelectuais) que resultou na materialização de interessantes fóruns e redes [...]. Tais coletivos $\backslash$ redes promovem variadas formas de enfrentamento em oposição a grandes projetos. Atuam no campo jurídico, articulam associações nacionais e internacionais para a defesa de seus direitos; demandam os Ministérios Públicos Estadual e Federal e cortes internacionais, como a Organização dos Estados Americanos (OEA). (ALMEIDA; SANTOS; SOUSA, 2018, p. 10 - 11)

As Organizações da Sociedade civil que se destacam na Amazônia promovem inclusão social e disseminam tecnologias sociais que superam o assistencialismo, colaborando com o protagonismo das Amazônias e dos seus amazônidas.

\section{OSC SEARA - (R)existência, inclusão social e promoção de vida a partir dos saberes Amazônidas}

A Associação Santarena de Estudos e Aproveitamento dos Recursos da Amazônia - SEARA - é uma OSC santarena, fundada em 6 de janeiro de 1979 com sede atualmente na Rua das Nações Unidas, 114, bairro de Santana. É uma entidade civil, sem fins econômicos, de natureza associativa, que, segundo o Código Civil brasileiro, "constituem-se as associações pela união de pessoas que se organizem para fins não econômicos" (art. 53). 
A união de pessoas que constituiu a SEARA deu-se a partir dos anos 70, diante da preocupação inicial dos médicos Clara Terko Takaki Brandão, pediatra e nutróloga, e Rubens Brandão, médico cirurgião, com os casos de crianças acometidas pela desnutrição no Município de Santarém.

No período de construção da Transamazônica, [...] nos mudamos para Santarém, no baixo Amazonas. [...] No $1^{\circ}$ dia do ambulatório me deparei com 15 crianças desnutridas graves: marasmo e kwashiorkor. Foi quando a $\mathrm{LBA}^{4}$ me procurou para ser presidente do núcleo de voluntariado para fundar 13 creches. Na época houve uma seca intensa, com falta de água ao lado do maior rio do mundo, e desnutrição em todos os bairros. Todavia, nenhum programa de alimentação em toda a região. A verba por criança era de uma passagem de ônibus por pessoa, e alimentação do café da manhã ao jantar, material de limpeza e brinquedos. (DRA. CLARA BRANDÃO, 2019)

Na época, a Dra. Clara realizou diversos estudos sobre os recursos da Amazônia e seu aproveitamento para a nutrição (ação que inspirou o nome da OSC SEARA), entre eles a observação participante, a história oral, o estudo da tabela nutricional dos alimentos e outros.

Fizemos hortas perenes em cada creche (necessitava pouca água), levantávamos com os idosos da comunidade os alimentos que eles comiam antigamente e os tipos de preparação e descobrimos que a segurança e a soberania alimentar devem se basear no bioma e estação do ano, sendo que os "matos comestíveis" da localidade são sempre orgânicos e muito ricos em micro-nutrientes.

$[\ldots]$

Aproveitamos todas as frutas da região como o caju, araçá, limão, cravo, pequi, laranja da terra, buriti, óleo e leite de babaçu, óleo de pequi, uso do jucá para melhorar a cicatrização, gergelim, coquinhos amarelos, etc; além de valorizar o artesanato: pilão de pau brasil de vários tamanhos, peneira de bambu e cipó, cestos, rendas de bilros, redes, etc. Óleo de copaíba, lambedor, etc. Difícil foi

\footnotetext{
${ }^{4}$ Legião Brasileira de Assistência (1942-1995), que implantou em 1976 o Projeto Casulo, o primeiro programa de educação infantil de massa no Brasil, mais um projeto do Governo Militar visando também a integração territorial.
} 
aprender a comer a farinha de mandioca caroçuda. (DRA. CLARA BRANDÃO, 2019)

Essas pesquisas resultaram na criação da Multimistura ${ }^{5}$ e, consequentemente, no sucesso das creches da SEARA. Relato:

A Multimistura surgiu após uma visita às plantações de pimenta do reino dos japoneses. Colocavam farelo de arroz como adubo, riquíssimo de minerais e vitaminas. Peneirando e torrando, o farelo exala cheiro de biscoito. Aleatoriamente passamos a usar 1 colher sopa/criança por dia e que se mostrou suficiente.

Em 3 dias a diarreia tinha acabado; os piolhos e a sarna desapareceram em função do complexo B; o impetigo desapareceu; melhorou a coordenação neuro-psicomotora controle do esfíncter; ganho de peso contínuo; redução das infecções, etc. (DRA. CLARA BRANDÃO, 2019)

Durante as primeiras décadas de atuação, a SEARA foi uma Sociedade de voluntários que manteve 13 creches em Santarém por meio do Projeto Casulo da Legião Brasileira de Assistência (LBA). O objetivo dessas creches da SEARA era a administração da multimistura na alimentação das crianças e a assistência nutricional e de saúde por meio da educação escolar, ou seja, a rotina das creches da SEARA, o seu objetivo e organização institucional possibilitaram a realização de um trabalho de educação na $1^{\mathrm{a}}$ infância diferenciado, focado principalmente nas temáticas sobre boa alimentação, reaproveitamento de alimentos, hábitos de higiene e alimentação regional, essa estratégia possibilitou a superação da desnutrição dos atendidos.

Com a diminuição do investimento da LBA, e a sua extinção em 1995, a SEARA passou por muitas dificuldades financeiras. Sem parcerias sólidas e buscando a sustentabilidade, a OSC precisou encerrar suas atividades na maioria das creches e passou a atender as crianças da educação infantil somente no Centro Educacional João de Barro, conhecido afetuosamente pela sociedade santarena como "Creche SEARA", com

\footnotetext{
${ }^{5}$ Complemento alimentar difundido pela SEARA e por outras OSCs do Brasil e do Mundo para o auxílio no combate à desnutrição protéico-calórico.
} 
educação formal e inscrição no MEC como "Entidade Conveniada" para atendimento na Educação Infantil; e na educação não escolar em atividades no Centro Integrado de Apoio e Formação Familiar (CIAFF) que atende adolescentes e jovens no contraturno escolar em atividades de arte e educação (PORTIFÓLIO INSTITUCIONAL - SEARA).

Figura 01: Registro da evolução de uma criança quando chegou à creche e depois do uso da Multimistura

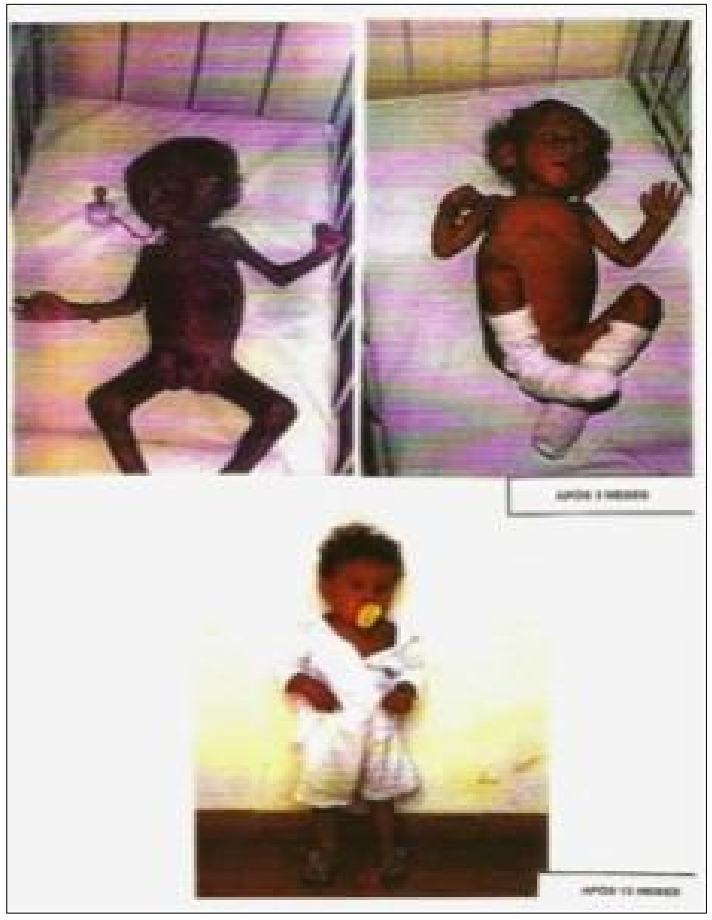

Fonte: BRANDÃO, Clara; 2019.

O pioneirismo da SEARA no trabalho de combate à desnutrição na primeira infância possibilitou o seu reconhecimento nacional e internacional, principalmente pelos resultados de sucesso alcançados ao longo de 40 anos. Relato:

[...] começamos a apresentar (a Multimistura e seus resultados) em congressos de Pediatria e dela recebemos, em 83, o prêmio Álvaro Bahia de melhor trabalho contra mortalidade infantil. Em 85 fui 
convidada para integrar a coordenação nacional da Pastoral da Criança. Já estava trabalhando no Ministério da Saúde. Treinamos líderes de todo o Brasil e de alguns países: Peru, Bolívia, Colômbia, Nicarágua, Moçambique e Angola. (DRA. CLARA BRANDÃO, 2019)

A sua metodologia inovadora de trabalho educacional na Amazônia que circunda: a educação nutricional intensiva com as crianças e suas famílias; a organização institucional; a prática pedagógica engajada na visão e missão da Entidade; a formação de professores em educação infantil, nutrição regional, saúde e as estratégias de seleção das crianças para atendimento; são o diferencial dessa OSC genuinamente amazônida e demonstração de (r)existência, inclusão social e promoção de vida, dignidade e direitos humanos.

RAPOSO; RAPOSO (2014, p. 35) afirma que "A legitimidade de uma organização [...] só pode ser atribuída de fora para dentro, e cabe à organização construí-la [...]. Se a entidade não é reconhecida enquanto ator legítimo pela sociedade - em nome de quem diz atuar - perde relevância", e por toda a sua trajetória e pioneirismo, o conhecimento e reconhecimento da SEARA deve ser contínuo.

\section{Considerações finais}

As reflexões ora apresentadas de maneira panorâmica e ao mesmo tempo específica, são resultados dos estudos e pesquisas realizadas acerca da realidade e da educação na Amazônia, observando aspectos singulares, a partir do olhar sobre as questões sociais, os direitos humanos e a inclusão, os quais aparecem intimamente relacionadas à exploração e também à educação, que por um lado interferem diretamente na vida e na formação humana dos amazônidas e por outro oferecem contribuições no sentido de desmistificar, de reconhecer ao mesmo tempo de valorizar a população que habita esta região.

Como se pode observar, esta pesquisa aponta para a educação como um diferencial, que pode e deve ser pensada como um instrumento contra hegemônico na região e na sociedade, de modo que atenda às 
necessidades dos menos favorecidos, muitas vezes, invisibilizados. E, ao considerarmos que o "fenômeno educativo manifesta-se, desde a origem do homem pelo desenvolvimento de processos educativos inicialmente coincidentes com o próprio ato de viver,[...]” (SAVIANI, 2016, p. 65), o entendimento desse processo educativo na produção da existência humana, nos mostra que a educação se constitui no "o ato de produzir, direta e intencionalmente, em cada indivíduo singular, a humanidade que é histórica e coletivamente produzida pelo conjunto dos homens."'SAVIANI, 1997, p. 13)

A partir dessa compreensão, destacamos que os diálogos apresentados sobre a Amazônia circundam a necessidade de olhar as "Amazônias" a partir da sua diversidade, "exigindo direitos e não favores". (GONÇALVES, 2010, p. 169) e nos argumentos expostos, sintetizamos a importância das Organizações da sociedade civil que promovem a inclusão social, em destaque para a OSC SEARA que na sua gênese revolucionou com um programa de saúde e nutrição genuinamente amazônida, associado a educação formal na $1^{\mathrm{a}}$ infância.

Entrementes, esta associação difere do papel da escola no formato dominante como quer o interesse capitalista, o qual

[...] coincide com a etapa histórica em que as relações sociais passaram a prevalecer sobre as relações naturais estabelecendo-se o primado do mundo da cultura (o mundo produzido pelo homem) sobre o mundo da natureza. [...] A etapa histórica em referência que ainda não se esgotou - corresponde ao surgimento e desenvolvimento da sociedade capitalista cujas contradições vão colocando de forma cada vez mais intensa a necessidade de sua superação. (SAVIANI, 2016, p. 65)

E, no que concerne a essa superação e à emancipação do homem, a educação tem papel fundamental no processo de difusão e construção de outros saberes, tal qual nas representações sociais e, neste sentido, a esse processo difusor e também educativo se somam os professores, como sujeitos atuantes na história da educação.

Ainda sobre o papel educacional, Paulo Freire, em diálogo com o Moacir Gadotti e Sérgio Guimarães, ressalta que: 
[...] uma educação [...] também tem a ver com a luta. Há uma educação revolucionária antes e outra depois que a revolução se instala. Antes ela não pode ser feita pelo poder que silencia, mas somente dentro dos movimentos sociais populares, dentro dos sindicatos, dentro dos partidos populares não populistas. E através de educadores que façam a sua conversão, o seu suicídio de classe, os pedagogos trânsfugas. Quando o grito se encarna no poder então a educação revolucionária toma outra dimensão, pois o que foi contestadora passa a ser agora educação sistematizada: trata-se então de recriar, de ajudar na reinvenção da sociedade. Na fase anterior ela ajudava o grito para a derrubada de um poder hostil às massas, com alas no poder a educação passa a ser um instrumento extraordinário de ajuda para a construção da sociedade nova, para a criação do homem novo. (GADOTTI; FREIRE; GUIMARÃES, 2015, p. 160).

Este argumento reflete o potencial das lutas e dos movimentos de resistências sobre as questões de direitos específicos e das políticas públicas para inclusão social. Trata-se da compreensão de que a educação, como prática revolucionária, propõe novas formas de organização da sociedade e esses movimentos possibilitam a governança, o protagonismo e a democratização do saber.

\section{Referências}

ALMEIDA, Rogério Henrique; SANTOS, Joelma Viana dos; SOUSA, Raimundo Valdomiro de. Amazônia(s) em rede(s): Rádios da Amazônia protagonizam comunicação alternativa a partir da Rádio Rural de Santarém/PA. Revista Observatório. Palmas, v. 4, n. 6, p. 898-926, out.-dez. 2018. Disponível em: $<$ https://sistemas.uft.edu.br/periodicos/index.php/observatorio/article/ download/5326/14256/> Acesso em: 23 jul 2020.

ALVES, Jaime Leônidas Miranda. Direitos fundamentais como realidade dialógica e a tutela judicial coletiva na construção da personalidade. Revista Jurídica Direito \& Paz, São Paulo, v. 6, n. 36, p. 139-156, abr, 2017.

Amazônia Revelada: os descaminhos ao longo da BR-163. Org.: Maurício Tor- 
res. Brasília: CNPq, 2005.

ANDRADE, Francisca Marli Rodrigues. A Amazônia além das florestas, dos rios e das escolas: representações sociais e problemas ambientais. Ambiente \& Sociedade. São Paulo. Vol. 21, 2018.

ARMANI, Domingos. Organizações da Sociedade Civil: Protagonismo e sustentabilidade. Barueri, SP: Instituto C\&A, 2013.

BRANDÃO, Clara. Relatos de experiências médicas no interior do Brasil, por Clara Brandão. 2019. Disponível em: <www.fmusp-turma52.com.br/ 2019/07/11/um-orgulho-da-52/\#comment-525>. Acesso em: 25 jul 2020.

CADERNOS DA AMAZÔNIA. Direitos humanos, desenvolvimento e luta social: desenvolvimento para quem? 2013. Disponível em: https://terradedireitos.org.br/uploads/arquivos/Cadernos-Amazonia\%281\%29.pdf. Acesso em: 21 jul 2020.

CASTRO, Valéria Coroa de; AMANAJÁS, Heriberto Wagner. Responsabilidade socioambiental e as ongs: estudo de caso do instituto capital social da amazônia / projeto de bancos comunitários. 2014. Disponível em: https:// www.eumed.net/rev/cccss/27/responsabilidad-ongs.html. Acesso em: 22 jul 2020.

COLARES, Anselmo Alencar. História, política e educação na Amazônia colonial. Material de circulação interna.

CRUZ, Valter do Carmo. R-existências, territorialidades e identidades na Amazônia. Terra Livre, Goiânia, v. 1, n. 26, p. 63-89, jan, 2006.

BRASIL. [Constituição (1988)]. Constituição da República Federativa do Brasil de 1988. Brasília, DF: Presidência da República, [2016]. Disponível em: http://www.planalto.gov.br/ccivil_03/Constituicao/Constituiçao.htm. Acesso em: 20 jul 2020.

BRASIL. Lei nº10.406 de 10 de janeiro de 2002. Institui o Código Civil. Disponível em < https://presrepublica.jusbrasil.com.br/legislacao/91577/codigocivil-lei-10406-02>. Acesso em 24 jul 2020.

COUTINHO, Rivanildo Monteiro. BRASILEIRO, Tânia Suely Azevedo. COSTA, Sinara Almeida. A discussão do termo gênero no currículo do curso de pedagogia no contexto universitário amazônico. In COLARES, Maria Lília Imbiriba Sousa; PEREZ, José Roberto Rus; CARDOZO, Maria José Pires Barros (org.). Educação e realidade amazônica - Volume 3. Uberlândia: Nave- 
gando Publicações, 2018, p. p.107-129. Disponível em: https://docs.wixstatic.com/ugd/35e7c6 814b679c39cb4139be9cbb56b727c0fa.pdf

GADOTTI, Moacir; FREIRE, Paulo; GUIMARÃES, Sérgio. Pedagogia: Diálogos e conflitos. 9 ed. São Paulo: Cortez, 2015.

GOMES, Marcela de Lima; CHAIBE, Maria Eduarda dos Santos. Educação, Linguagem e Amazônia. In: COLARES, Anselmo Alencar; COLARES, Maria Lilia Imbiriba Sousa (org.) Educação e realidade amazônica. Uberlândia: Navegando Publicações, 2016, p. 60-72. Disponível em: https://docs.wixstatic.com/ugd/35e7c6 877db987057646b79c466a958ea288e1.pdf

GONÇALVES, Carlos Walter P. Amazônia, Amazônias. $3^{a}$ ed. São Paulo: Contexto, 2010.

IBGE - INSTITUTO BRASILEIRO DE GEOGRAFIA ESTATÍSTICA. Reflexões sobre Censo. São Paulo, 2010. Disponível em: www.ibge.gov.br. Acesso em: 23 jul 2020.

LACERDA, Luiz Felipe; VERONESE, Marília Veríssimo. A questão social e o contexto amazônico. Cadernos do Ceas, Salvador/Recife, n. 240, p. 43-70, jan./abr., 2017.

MAPA DAS ORGANIZAÇÕES DA SOCIEDADE CIVIL. Disponível em <www.mapaosc.ipea.gov.br/>. Acesso em: 24 jul 2020.

MÉSZÁROS, István. A educação para além do capital. 2. ed. Tradução Isa Tavares. São Paulo: Boitempo, 2005.

MOURA, Fádya Lorena de Souza; FERREIRA, Ediene Pena. Educação e Diversidade: repensando o ensino de língua portuguesa no contexto amazônico. In COLARES, Maria Lília Imbiriba Sousa; PEREZ, José Roberto Rus; TAMBORIL, Maria Ivonete Barbosa (org.) Educação e realidade amazônica - Vol. 2. Uberlândia: Navegando Publicações, 2017, p. 23-36. Disponível em: https://docs.wixstatic.com/ugd/35e7c6_877db987057646b79c466a958ea288e1.pdf

MULTIMISTURA. Disponível em < www.multimistura.org.br/novo/> . Acesso em: 25 jul 2020.

OLIVEIRA, Anna Cynthia; HADDAD, Sérgio. As Organizações da Sociedade Civil e as ONGs em Educação. Cadernos de Pesquisa UFGD, n 112, p. 61-83, mar 2001. Disponível em: <www.scielo.br/pdf/cp/n112/16101.pdf>. Acesso em: 25 jul 2020. 
ONU. Declaração Universal dos Direitos Humanos. 1948. Disponível em: https://www.ohchr.org/EN/UDHR/Pages/Language.aspx?LangID=por.

Acesso em: 12 jul 2020.

OUTEIRO, Gabriel Moraes de; SOARES, Daniel de Sousa. Direitos humanos, antropologia do desenvolvimento e Amazônia: a importância do saber local. II Encontro de Pós Graduação da Unifesspa, Marabá, v. 1, p. 2-9, mar, 2017.

RAPOSO; Rebecca; RAPOSO, Mariana Tavares. Uma experiência em fortalecimento institucional de organizações sem fins lucrativos. São Paulo, SP: Via impressa Edições de Arte, 2014.

RIBEIRO, Vanuza Campos. BRASILEIRO, Tânia Suely Azevedo. A educação pública na Amazônia brasileira e o atual contexto das parcerias público-privadas. In COLARES, Maria Lília Imbiriba Sousa; PEREZ, José Roberto Rus; TAMBORIL, Maria Ivonete Barbosa (org.) Educação e realidade amazônica - Vol. 2. Uberlândia: Navegando Publicações, 2017, p. p.163-185. Disponível em: https://docs.wixstatic.com/ugd/35e7c6_877db987057646b79c466a958ea288e1.pdf

RODRIGUES, Saulo Tarso. O modelo de racionalidade ocidental (razão indolente) e os direitos humanos: uma crítica ao conceito hegemônico de cidadania a partir da sociologia das ausências de boaventura de sousa santos. Revista de Educação Pública, Cuiabá, v. 16, n. 31, p. 69-82, maio, 2007.

RODRIGUES, Isabela Feijó Sena; RIBEIRO, Cristina Figueiredo Terezo. Violação dos direitos humanos na Amazônia: uma análise dos casos na Comissão Interamericana de Direitos Humanos envolvendo povos tradicionais. Revista de Direitos Humanos em Perspectiva, Curitiba, v. 2, n. 2, p. 22-38, jul. 2016. SANTOS, Christiane Jorge Rosa dos. O Direito ao Ambiente e o Princípio da Dignidade da Pessoa Humana como fundamentos da Dimensão Social da Sustentabilidade. Saberes da Amazônia, Porto Velho, v. 3, n. 7, p. 90-107, jul. 2018.

SANTOS, Boaventura de Souza. A reinvenção solidária e participativa do Estado. IN Pereira, Luis Carlos Bresser (Org.). Sociedade e Estado em Transformação. São Paulo: Unesp, 2001, p. 13.

SARLET, Ingo Wolfgang. A eficácia dos direitos fundamentais. $2^{a}$ ed. Porto Alegre: Livraria do Advogado, 2001. 
SAVIANI, Demerval. Educação escolar, currículo e sociedade: o problema da Base Nacional Comum Curricular. Movimento - Revista de Educação do PPFE/UFF. Ano 3, número 4, 2016.

SAVIANI, Demerval. Pedagogia histórica crítica. Campinas-SP: Autores associados, 1997.

SEARA. Estatuto Social da SEARA. Santarém/PA, 2016.

SEARA. Portfólio Institucional - SEARA. Santarém/PA, 2015.

SEARA. Projeto Político Pedagógico - Biênio 2016 e 2017. Santarém/PA, 2015.

SILVA JÚNIOR, João dos Reis, et al. Das crises do capital às crises da educação superior no Brasil: novos e renovados desafios em perspectiva. Uberlândia: Navegando Publicações, 2019.

VIEIRA, Flávia do Amaral. Direitos humanos e desenvolvimento na Amazônia: Belo Monte na Comissão Interamericana de Direitos Humanos. 2015. 245 f. Dissertação (Mestrado) - Curso de Mestrado em Direito e Relações Internacionais, Universidade Federal de Santa Catarina, Florianópolis, 2015. 
